\title{
MANFAAT, PENDUKUNG, HAMBATAN, PELAKSANAKAN DAN DAMPAK KETIDAKTEPATAN PELAKSANAAN SUPERVISI TERHADAP PERAWAT DI RUMAH SAKIT: TINJAUAN LITERATUR
}

\section{USEFUL, SUPPORTING FACTOR, BARRIERS, IMPLEMNETATION AND IMPACT INACCURACY SUPERVISION IMPLEMENTATION OF NURSE AT HOSPITAL; LITERATURE REVIEW}

\author{
Nunik Suryanti ${ }^{1}, \operatorname{Rr}$ Tutik Sri Hariyati ${ }^{2}$ \\ ${ }^{1}$ Program Magister Ilmu Keperawatan, Fakultas Ilmu Keperawatan, Universitas Indonesia \\ ${ }^{2}$ Departemen Keilmuan Dasar Keperawatan dan Keperawatan Dasar, \\ Fakultas Ilmu Keperawatan, Universitas Indonesia \\ e-mail: gendiskayla37@gmail.com
}

\begin{abstract}
ABSTRAK
Keterbatasan rasio tenaga perawat menyebabkan bagaimana dengan jumlah staf perawat yang terbatas, namun pelayanan keperawatan yang diberikan tetap berkualitas tinggi, salah satu strateginya yaitu dengan pengarahan dan pengawasan yang dilakukan kepala ruang melalui supervisi. Literatur ini bertujuan memberikan informasi berkaitan dengan supervisi keperawatan, terkait manfaat, pendukung, hambatan, pelaksanaan supervisi dan dampak supervisi yang dilaksanakan tidak efektif di rumah sakit. Metode: dengan melakukan penelusuran literatur yang dipublikasikan online pada tahun 2012 sampai 2020, di WILEY, PROQUEST, CINAHL, MEDLINE. Hasil: Manfaat supervisi adalah mendukung dalam pengembangan professional, pelaksanaan kode etik, meningkatkan kelengkapan dan kualitas asuhan dan pelayanan keperawatan maupun dokumentasi asuhan keperawatan, serta membantu dalam transisi peran seorang perawat. Supervisi yang efektif dilakukan dengan secara individu dan berkelompok, dengan durasi dan frekuensi yang efektif. Dampak supervisi yang tidak tepat dan cenderung abusif dapat menimbulkan contraproduntive behavior work (CWB) yang justru dapat menimbulkan kerugian bagi organisasi. Kesimpulan: Supervisi efektif dilaksanakan dengan memperhatikan jenis, durasi, frekuensi, menggunakan pendekatan interpersonal, dan menghindari supervisi yang cenderung abusif sehingga dapat diperoleh manfaat dan mencegah timbulnya dampak psikososial dan CWB yang dapat merugikan rumah sakit atau organisasi.
\end{abstract}

Kata kunci: Perawat, Supervisi, Supervisi Efektif

\begin{abstract}
The limited ratio of nurses causes what about the limited number of nursing staff, but the nursing services provided remain high quality. One of the strategies being the actuating and controlling by head nurse with carried out through supervision. (Objective) this literature review is to provide information relating to nursing supervision, related to the benefits, facilitating, barriers, implementation of supervision, and the impact of supervision that is implemented ineffective in hospitals. Method: searching literature published online in 2012 to 2020, on WILEY, PROQUEST, CINAHL, MEDLINE. Results: The benefits of supervision are support in professional development, implementation of the code of ethics, improving the completeness and quality of care and nursing services as well as documentation of nursing care, and helping in the transition of the role of a nurse. Effective supervision can be done one to one, group, with a effective duration and a frequency. Effective supervision can also be done with an interpersonal approach, the presence of senior roles, the presence of feedback, and opportunities to reflect on themselves. The impact of improper supervision and tend to be abusive can lead to counterproductive behavioral work (CWB) which can actually cause harm to the organization. Conclusion : Effective supervision is carried out by paying attention to type, duration, frequency, , using an interpersonal approach, and avoiding supervision that tends to be abusive so that benefits can be obtained and prevent the emergence of psychosocial and CWB impacts that can harm the hospital or organization.
\end{abstract}

Key words: Effective Supervision,Nurse, Supervision 


\section{PENDAHULUAN}

Keterbatasan jumlah tenaga kesehatan. menjadi salah satu hambatan cakupan kesehatan universal (Universal Health Coverage) yang harus dicapai tahun 2030. Kenyataannya, jumlah tenaga kesehatan di sebagian besar negara berkembang belum mencapai 22,8 per 10.000 penduduk, hal ini belum sesuai rekomendasi World Health Organization ${ }^{1}$. Tenaga perawat di Indonesia tahun 2016 baru mencapai 113,40 per 100.000 penduduk atau $49 \%$ dari jumlah tenaga kesehatan ${ }^{2}$. Padahal, UHC terjadi pergeseran berkonsep pelayanan yang terintegrasi, pasien sebagai fokus pelayanan, ${ }^{3}$.

Pelayanan keperawatan yang tetap berkualitas tinggi dengan jumlah perawat terbatas dapat dicapai melalui kepemimpinan, pengawasan, dukungan, memotivasi, mengembangkan potensi staf melalui supervisi kepala ruang ${ }^{1}$. Staf yang menerima umpan balik positif dan potensinya dikembangkan, akan meningkatkan produktifitas dan budaya kerja staf ${ }^{4}$.

Supervisi adalah salah satu fungsi pengarahan dalam manajemen yang bersifat komplek, adanya komunikasi, berpikir kritis, memotivasi, memberi petunjuk, pemahaman dan pengetahuan tentang ruang lingkup praktik dan pekerjaannya $^{5}$. Supervisi adalah proses formal yang mendukung pengembangan pengetahuan, ketrampilan, dan akuntabilitas, dengan kerangka kerja konseptual, mengajarkan, agar kualitas dan keamanan pasien meningkat ${ }^{6}$.

Kenyataannya menunjukkan bahwa pencapaian supervisi, pengarahan dan pengendalian kepala ruang masih rendah. Capaian supervisi yang dilaksanakan hanya sebesar $32 \% 7$. Pengarahan dan pengendalian yang baik hanya $20 \%^{8}$, sedangkan fungsi pengarahan yang baik hanya sebesar $61,6 \%,{ }^{9}$.

Supervisi yang baik berdampak positif terhadap kinerja perawat dalam asuhan keperawatan $^{10}$, meningkatnya tindakan perawatan luka sesuai standar sebesar $20 \%^{11}$ dan meningkatkan pendokumentasian asuhan keperawatan sebesar $8,8 \%{ }^{12}$.

Sebaliknya supervisi yang tidak baik berdampak pada pendokumentasian dan kualitas asuhan, dan meningkatnya kesalahan perawat (nursing error) hingga berdampak pada kematian pasien. Supervisi yang tidak baik menghambat pendokumentasian asuhan keperawatan $^{13}$, kualitas asuhan serta pelayanan keperawatan kurang ${ }^{14}$. Supervisi yang kurang sebagai penyebab terbesar kesalahan perawat (nursing error), dari 300 kasus nursing error yang dilaporkan $40 \%$ diantara berdampak pada kematian pasien ${ }^{15}$.

Supervisi yang tidak tepat, dan cenderung abusif dapat menimbulkan kontraproduktif dan abusif. Data menunjukkan supervisi yang dilakukan abusif 46,64 \%, dan 36,6\% menimbulkan ketidakpatuhan dan produktifitas kerja yang menurun dan perilaku kerja tidak produktif (contraproductive work behavior atau CWB) perawat yang berdampak pada rumah sakit, kualitas perawatan maupun kepada pasien ${ }^{16}$. Tindakan CWB minimal akan dilakukan sekali dari $95 \%$ perawat yang mendapatkan supervisi yang bersifat abusif ${ }^{17}$. 
Sebuah studi literatur diperlukan untuk memberikan informasi terkait supervisi agar dapat meningkatkan pemahaman dan wawasan tentang supervisi yang efektif. Tinjauan literatur ini bertujuan untuk memberikan informasi tentang supervisi keperawatan, terkait manfaat, pendukung, hambatan dan pelaksanaan supervisi yang efektif, maupun dampak supervisi yang dilaksanakan tidak tepat dan cenderung abusif di rumah sakit.

\section{METODE}

Metode yang digunakan adalah melakukan tinjauan literature melalui penelusuran terhadap artikel jurnal yang relevan yang dipublikasikan pada tahun 2013 hingga 2020, berbahasa Inggris, jurnal open access, hasil penelitian terkait pelaksanan supervisi di rumah sakit, dengan mengecualikan hasil penelitian supervisi yang dilakukan di pendidikan dan di public health care (PHC). Penelusuran dilakukan terhadap jurnal yang diterbitkan secara online melalui WILEY, PROQUEST, CINAHL, MEDLINE dengan menggunakan kata kunci supervisi, supervisi keperawatan, supervisi dan keperawatan.

\section{HASIL}

Hasil penelusuran dan diklasifikasikan, terdiri dari definisi, manfaat, faktor pendukung, hambatan, pelaksanaan supervisi efektif, dan dampak pelaksanaan supervisi yang tidak dilaksanakan dengan tepat.

Supervisi adalah sebuah proses yang bertujuan membantu perubahan orang yang disupervisi untuk meningkatkan ketrampilan praktik, kemampuan teoritis dan teknis, mengembangkan personal dan profesional. Supervisi adalah proses terintegrasi dengan praktik perawatan melalui dukungan dan pembelajaran untuk memberikan pelayanan yang aman, meningkatkan kompetensi dan dukungan pada professional secara individu untuk bekerja dalam situasi yang penuh stress ${ }^{18}$. Supervisi adalah alat kerja manajemen terhadap pengetahuan dan praktik, pekerjaan sebagai bentuk kinerja manajemen dan perawatan terkait pengembangan kemampuan tim keperawatan ${ }^{19}$.

Manfaat supervisi ditinjau dari jenis supervisi yaitu supervisi formatif bermanfaat staf menyadari perilakunya, mempelajari lebih lanjut tentang asuhan keperawatan dan tanggung jawab, mempertahankan standar profesional dan kualitas asuhan keperawatan, supervisi normatif bermanfaat meningkatkan kemampuan melihat pekerjaan lebih obyektif, meningkatkan tanggungjawab dan kepatuhan, mengembangkan keterampilan dan pengetahuan, sedangkan supervisi restoratif bermanfaat mengurangi stres, meningkatkan komunikasi dengan tim ${ }^{20,21}$.

Supervisi bermanfaat meningkatkan rasa percaya diri dan tanggung jawab staf, meningkatkan profesional dan pelaksanaan kode etik, kualitas perawatan serta alat manajemen kinerja dan salah satu cara delegasi pekerjaan $^{22}$. Supervisi bermanfaat meningkatkan kelengkapan asuhan dan pelayanan perawatan, meningkatkan hubungan 
sosial, alat menilai kualifikasi dan kelengkapan pencatatan asuhan keperawatan, memantau asuhan keperawatan dan audit dalam perawatan kesehatan, sehingga terlaksana asuhan dan pelayanan keperawatan berfokus pada pasien.

Supervisi juga bermanfaat membantu perawat dalam transisi peran. Transisi peran adalah dimana seorang perawat merasa tidak nyaman, penuh tekanan melakukan peran baru, mengalami proses perubahan, melepaskan cara lama dan mengembangkan cara baru, beradaptasi dengan keterampilan yang baru, membangun identitas dan citra diri dari peran yang baru ${ }^{23}$.

Faktor pendukung pelaksanaan supervisi adalah adanya peran senior dalam supervisi. Supervisi yang dilakukan perawat senior minimal 7,522,5/minggu bermanfaat meningkatkan keamanan bagi pasien dan perawat. Faktor pendukung pelaksanaan supervisi perawat senior adalah ketersediaan waktu, kesediaan kepala ruang mendiskusikan hasil supervisi, dukungan perawat, kemampuan supervisi, kesiapan dan dukungan terhadap peran dan ketrampilan leadership yang adekuat. Adapun faktor penghambatnya adalah kompleksitas budaya, kebutuhan memanajemen pasien, pekerjaan administratif, kompleksitas pekerjaan, ketidakhadiran staf, kurangnya kebijakan, dukungan peran dan rasa percaya $\operatorname{diri}^{24}$.

Hambatan supervisi yaitu ruangan tidak privasinya, konflik politik dan profesional, kurangnya pemahaman, waktu perawat dan sumber daya perawatan kesehatan. Hambatan dari perawat termasuk adanya ketakutan terhadap perubahan, kurangnya kepercayaan, pengetahuan, keterampilan atau pemahaman yang kurang ${ }^{25}$. Hambatan dalam supervisi yaitu staf menghadiri supervisi apabila diberikan fee sebagai pengganti biaya membayar penitipan anak, sibuk, kekurangan staf, kurangnya pemahaman tentang supervisi dan bagaimana mendorong staf untuk merefleksikan diri serta masalah pribadi yang tidak berhubungan dengan pekerjaan, dan konflik antara individu maupun manajemen ${ }^{26}$.

Supervisi sebaiknya dilakukan frekuensi supervisi dilakukan 1 kali dalam satu minggu, dan dievaluasi setiap 8 minggu, durasi 45 menit - 2 jam untuk supervisi berkelompok, dan 1 jam untuk supervisi individu dan dievaluasi kembali minimal setiap 3 bulan. Staf mengharapkan harus menerima supervisi atau pengawasan setiap 4-6 minggu sekali.

Supervisi yang efektif adalah supervisi yang dirasakan aman, merefleksikan diri, professional, menjaga emosi namun berbeda dengan interaksi sosial, membantu mengatasi perasaan perawat yang dialami dari hari ke hari ketika melakukan pekerjaan. Supervisi dilakukan fleksibel, perhatian, memotivasi menghormati, menghargai, mengakui keterampilan, pengetahuan, kompetensi, yang dicapai staf, ada umpan balik dan penguatan positif, adanya dukungan dan profesional. proaktif, ada informasi, petunjuk, bimbingan, mengajarkan dan melatih staf dan yang tak kalah penting adalah menanggapi kebutuhan dan memecahkan masalah staf tepat waktu ${ }^{27}$. 
Supervisi efektif bila dilakukan dengan memperhatikan isi supervisi, terstruktur, didokumentasikan, dan menggunakan formulir terstandar, dilakukan pimpinan, kepala ruang atau fasilitator dengan pengalaman minimal dua tahun. Jenis supervisi dilakukan secara tatap muka baik secara individu, peer group maupun berkelompok.

Supervisi efektif dilakukan dengan memberikan kesempatan merefleksikan diri, refleksi diri adalah proses aktif dan disengaja dari praktik di mana seorang individu diminta menilai diri sendiri untuk mewujudkan praktik yang diinginkan dan efektif, mengurangi kecemasan, kebingungan, dan keraguan terutama perawat pada tahap awal transisi. Supervisi efektif fleksibel, ada proses, pendekatan dan hubungan sosial, sesuai kebutuhan, mendidik, menggunakan keterampilan teknis, manajemen, hubungan interpersonal dan interaksi untuk memahami orang, adanya timbal balik serta adanya refleksi diri.

Supervisi transisi peran perawat dilakukan dengan meninjau kasus secara retrospektif secara formal, dengan refleksi diri, untuk mengetahui makna dari pengalaman. Teknik reflektif adalah proses aktif secara sengaja setiap individu terhadap praktik dengan menilai diri sendiri, bertanya, mengeksplorasi pengetahuan dan perspektifnya, keterampilan dan eksperimen, menghubungkan teori dan praktik, dan mengembangan kompetensi yang dimilikinya ${ }^{23}$.

Supervisi yang tidak tepat berdampak adanya rasa tertekan, pengalaman tidak baik, menangis, merasa dianggap tidak berkontribusi, cemas, merasa dikucilkan ${ }^{28}$. Supervisi yang tidak tepat dan cenderung abusif berdampak timbulnya contraproductive work behavior (CWB) yang berupa beristirahat lebih lama, mengabaikan instruksi, sengaja bekerja lebih lambat, terlambat masuk kerja, depresi, kecemasan, harga diri rendah, kemarahan, ketidakberdayaan, balas dendam, rasa malu, menurunnya semangat kerja, penurunan produktivitas dan pelayanan perawatan, meningkatnya kesalahan dan hanya sedikit perawat yang mengalami supervisi abusif tidak melakukan perilaku negatif ${ }^{29}$.

\section{PEMBAHASAN}

Supervisi merupakan proses meningkatkan ketrampilan praktik, kemampuan teoritis, mengembangkan personal dan profesional agar memberikan pelayanan yang aman dan sesuai standar. Supervisi adalah proses formal pendukung profesionalisme dan mengembangkan pengetahuan dan kompetensi, meningkatkan pelaksanaan praktik dengan tanggungjawab untuk meningkatkan kualitas dan perlindungan dan keselamatan pasien dalam menerima perawatan ${ }^{30,32,32}$.

Ditinjau dari jenis supervisi, supervisi formatif bermanfaat dalam pengembangan keterampilan, pemahaman dan pencapaian kompetensi melalui refleksi dan eksplorasi pencapaian pekerjaan yang dilakukan, fungsi normatif bermanfaat dalam mengontrol kualitas dan keamanan pemberian perawatan, memastikan kode etik profesional, pedoman, standar dan 
prinsip-prinsip dipatuhi dan tujuan organisasi tercapai, sedangkan supervisi restoratif bermanfaat memberikan dukungan emosional, kesehatan dan kesejahteraan mental perawat, menurunkan kelelahan dan menahan emosi melaluai sesi non formal.

Manfaat supervisi adalah membantu mengembangkan profesional, meningkatkan pelaksanaan kode etik, kualitas dan kelengkapan perawatan asuhan dan pelayanan perawatan, meningkatkan hubungan sosial, alat menilai kualifikasi dan kelengkapan pencatatan asuhan keperawatan dengan percaya diri dan rasa tanggungjawab serta sebagai audit pelayanan dan asuhan keperawatan. Manfaat supervisi adalah mengembangkan keterampilan dan kompetensi profesional, mengurangi stres dan kelelahan, mengurangi cuti akibat sakit, meningkatkan kepuasan kerja, meningkatkan pengembangan professional dan praktik yang $\operatorname{aman}^{31}$.

Adapun faktor pendukung terlaksananya supervisi yaitu adanya peran senior, delegasi supervisi, tersedia waktu untuk pelaksanaan supervisi, tersedianya lingkungan yang privasi, pengetahuan dan ketrampilan yang dimiliki manajer yang melakukan supervisi. Pelaksanaan supervisi membutuhkan kemampuan keterampilan kognitif, afektif, dan psikomotorik, termasuk kemampuan komunikasi, memotivasi, membimbing, pengarahan, kepemimpinan, dan memiliki pengalaman $^{31}$. Supervisor yang memiliki pengalaman dapat diperoleh ide dan pemikiran dalam pengembangan praktik keperawatan ketika memberikan pengarahan dan bimbingan ${ }^{34}$.

Hambatan supervisi dapat berupa faktor eksternal dan internal staf. Faktor eksternal staf seperti kurangnya pengetahuan ketrampilan, dan kemampuan mendorong staf merefleksikan diri, ruangan kurang privasi, kurangnya waktu perawat maupun manajer untuk melakukan supervisi sedangkan faktor internalnya seperti ketakutan terhadap perubahan, kurangnya kepercayaan, pengetahuan dan keterampilan, banyaknya tugas administratif. Waktu dan lingkungan merupakan faktor penghambat pelaksanaan pengawasan atau supervisi ${ }^{32}$.

Pelaksanaan supervisi yang efektif dilakukan secara formal dan informal, memperhatikan aspek etik. didokumentasikan, terstruktur, menjaga privasi dan memberikan kesempatan merefleksikan diri dan umpan balik (feedback) yang tepat. Supervisi efektif dilakukan dengan spesifik dan meminta umpan balik staf ketepatan konten dan sesi pengawasan, dan kesempatan refeksi diri staf ${ }^{(34)}$, menggunakan lebih dari satu cara, membina hubungan positif, tidak menghakimi, memotivasi, berempati, konsisten, peduli dan sopan, menggunakan pendekatan interpersonal dan komunikasi, dan memberi umpan balik positif dan konstruktif. Keberhasilan pengarahan tercapai apabila dilaksanakan teratur dan berkala, lebih dari satu kali, dengan pengamatan langsung, segera memberikan pengarahan edukatif, supportif dan objektif, bersifat fleksibel dan menyesuaikan perkembangan bawahan yang disupervisi atau diarahkan ${ }^{35}$. 
Supervisi efektif dapat dilakukan secara individu (one to one) maupun berkelompok (group). Pelaksanaan supervisi efektif dapat dilakukan secara individu (one to one), berkelompok (group), peer group dan multiprofesional maupun dikombinasikan ${ }^{36,37}$.

Supervisi efektif dapat dilaksanakan dengan memperhatikan durasi supervisi yang efektif dilakukan 45 menit sampai 2 jam, dengan frekuensi setidaknya satu kali seminggu maupun minimal sekali dalam tiga bulan. Durasi supervisi efektif dilakukan minimal 3060 menit, minimal satu bulan sekali ${ }^{34}$. Apabila durasi dalam supervisi hanya 1-3 menit, menjadi salah satu penghambat supervisi yang efektif ${ }^{38}$.

Supervisi yang tidak tepat seperti mengancam berdampak pada psikologis staf dan menimbulkan contraproductive work behavior (CWB). Ketidaktepatan supervisi dan cenderung melecehkan menimbulkan perilaku menghindari supervisi, perilaku membahayakan lingkungan kerja, kelelahan, menghindari feedback (umpan balik), di Amerika dilaporkan merugikan organisasi $\$ 23$ miliar per tahun ${ }^{39}$. Supervisi efektif adalah supervisi yang dilakukan dengan tidak mengancam, tidak menghakimi namun dilakukan dengan peduli dan sopan, melalui pendekatan interpersonal dan komunikasi ${ }^{34,35}$.

\section{KESIMPULAN}

Supervisi memiliki peranan penting dalam upaya peningkatan kelengkapan dan kualitas asuhan dan pelayanan keperawatan, pengembangan profesional, pelaksanaan kode etik serta membantu transisi peran perawat baru. Sebaliknya, supervisi yang dilaksanakan tidak tepat dan cenderung abusif dapat menimbulkan dampak psikilogis dan contraproductive work behavior (CWB) oleh staf yang justru akan merugikan organisasi.

Pelaksanaan supervisi efektif dapat dilakukan secara individu, berkelompok maupun multiprofesional, dengan memperhatikan frekuensi dan durasi yang tepat. Pelaksanaan supervisi juga memperhatikan jenis, dengan cara yang tepat, bersifat edukatif, meskipun supervisi dapat bersifat fleksibel.

Pelaksanaan supervisi efektif memerlukan ketersediaan lingkungan yang privasi, menggunakan pendekatan atau hubungan sosial dan interpersonal, adanya feedback dan memberikan kesempatan staf untuk merefleksikan diri terkait pencapaian praktik dan kompetensinya, dan adanya peran senior yang menerima delegasi untuk melakukan supervisi.

Hal yang tak kalah penting lainnya dalam pelaksanaan supervisi efektif yaitu diperlukannya kemampuan afektif, psikomotorik, kognitif kepala ruang, serta didukung dengan kemampuan leadership, manajerial dan interpersonal, meskipun waktu menjadi salah satu faktor penghambatnya. Kemampuan yang diperlukan tersebut dapat diperoleh melalui dukungan organisasi seperti pemberian pelatihan supervisi bagi kepala ruang. 


\section{DAFTAR PUSTAKA}

1. Kakyo TA, Xiao LD. Challenges faced in rural hospitals: the experiences of nurse managers in Uganda. Int Nurs Rev. 2019;66(1):70-7.

2. Kementerian Kesehatan Republik Indonesia. Situasi tenaga keperawatan di Indonesia [Internet]. 2017. p. 1-12. Available from: http://www.depkes.go.id/resources/dow nload/pusdatin/infodatin/infodatin perawat 2017.pdf

3. World Health Organization. Tokyo declaration on universal health coverage: All together to accelerate progress towards UHC [Internet]. Universal Health Coverage Forum 2017. 2017. Available from: https://www.who.int/universal_health_c overage/tokyo-decleration-uhc.pdf?ua=1

4. Brockner J, Flynn FJ, Dolan RJ, Ostfield A, Pace D, Ziskin I V. Commentary on "radical HRM innovation and competitive advantage: The Moneyball story." Hum Resour Manage. 2016;45(1):127-45.

5. Huber D. Leadership nursing care management. 5th editio. Iowa. St. Louis Missouri: Elsevier Saunders; 2014.

6. Pires R, Reis Santos M, Pereira F, Rocha I. Most relevant clinical supervision strategies in nursing practice. 2016;351-61.

7. Harmatiwi D, Sumaryani S, Maria E. Evaluasi Pelaksanaan Supervisi Keperawatan di Rumah Sakit Umum Daerah Panembahan Senopati Bantul. J Medicoeticolegal dan Manaj Rumah
Sakit 1018196/jmmr2016. 2017;6(1):47-54.

8. Machudo, Mohidin. Nursing documentation study at Teaching Hospital in KSA. Nurs Heal. 2015;3(1):1-6.

9. Fithriyani, Wahyuni F, Priscillia V. Analisis hubungan fungsi manajerial kepala ruangan dengan kualitas dokumentasi asuhan keperawatan di ruang rawat inap RSUD Pariaman. J Akad Baiturrahim. 2017;6(1):7-16.

10. Zulkarnain. Analisis Pelaksanaan Fungsi Manajemen Pengarahan Kepala Ruangan Dengan Kinerja Perawat Dalam Menerapakan Asuhan Keperawatan di Ruang Rawat Inap RSUD Bima. 2017;1(2).

11. Widiyanto P, Hariyati T, Handiyani $H$. Pengaruh pelatihan supervisi terhadap penerapan supervisi klinik kepala ruang dan peningkatan kualitas tindakan perawatan luka Di RS PKU Muhammadiyah Temanggung. Pros Konf Nas PPNI Jawa Teng [Internet]. 2013;44-51. Available from: http://jurnal.unimus.ac.id/index.php/psn 12012010/article/viewFile/848/902

12. Rosa EM. Efektivitas penerapan supervisi kepala ruang terhadap pelaksanaan pendokumentasian asuhan keperawatan di ruang rawat inap Rumah Sakit Pku Muhammadiyah Bantul. JMMR (Jurnal Medicoeticolegal dan Manaj Rumah Sakit). 2012;1(2).

13. Vafaei SM, Manzari ZS, Heydari A, Froutan R, Farahani LA. Nurses' perception of nursing services 
documentation barriers: A qualitative approach. Electron J Gen Med. 2018;15(3):3-10.

14. Oktaviani M, Rofii M. Gambaran pelaksanaan supervisi kepala ruang terhadap perawat pelaksana dalam keselamatan pasien. J Kepemimp dan Manaj Keperawatan [Internet]. 2019;2(1):23-7. Available from: https://journal.ppnijateng.org/index.php/ jkmk/article/view/165

15. Davys AM, O’Connell M, May J, Burns B. Evaluation of professional supervision in Aotearoa/New Zealand: An interprofessional study. Int J Ment Health Nurs. 2017;26(3):249-58.

16. Estes B. Abusive supervisi and nursing performance. 2013;48(1).

17. Low YM, Sambasivan M, Ho JA. Impact of abusive supervision on counterproductive work behaviors of nurses. Asia Pacific J Hum Resour. 2019;(May):1-29.

18. Pollock A, Campbell P, Deery R, Fleming M, Rankin J, Sloan G, et al. A systematic review of evidence relating to clinical supervision for nurses, midwives and allied health professionals. J Adv Nurs. 2017;73(8):1825-37.

19. Chaves LDP, Mininel VA, Silva JAM da, Alves LR, Silva MF da, Camelo SHH. Nursing supervision for care comprehensiveness. Rev Bras Enferm. 2017;70(5):1106-11.

20. MacLaren J, Stenhouse R, Ritchie D. Mental health nurses' experiences of managing work-related emotions through supervision. J Adv Nurs. 2016;72(10):2423-34.

21. Brunero S, Lamont S. The process, logistics and challenges of implementing clinical supervision in a generalist tertiary referral hospital. Scand J Caring Sci. 2012;26(1):186-93.

22. Tobias C, Ives JE, Garnham AP. Nursing supervision: challenges and opportunities for success. Learn Disabil Pract. 2016;19(6):33-8.

23. Sharrock J, Javen L, Mcdonald S. Clinical supervision for transition to advanced practice. Perspect Psychiatr Care. 2013;49(2):118-25.

24. Rankin J, Mcguire C, Matthews L, Russell M, Ray D, on behalf of the Leading Better Care Research. Facilitators and barriers to the increased supervisory role of senior charge nurses: A qualitative study. J Nurs Manag. 2016;24(3):366-75.

25. Escrig-Pinol A, Corazzini KN, Blodgett $\mathrm{MB}, \mathrm{Chu} \mathrm{CH}, \mathrm{McGilton} \mathrm{KS}$. Supervisory relationships in long-term care facilities: A comparative case study of two facilities using complexity science. J Nurs Manag. 2019;27(2):3119.

26. Kenny A, Allenby A. Nurse Education in Practice Implementing clinical supervision for Australian rural nurses. Nurse Educ Pract. 2013;13(3):165-9.

27. Chu $\mathrm{CH}$, Ploeg J, Wong $\mathrm{R}$, Blain J, McGilton KS. An Integrative Review of the Structures and Processes Related to Nurse Supervisory Performance in Long-Term Care. Worldviews 
Evidence-Based Nurs. 2016;13(6):4119.

28. Buus N, Delgado C, Traynor M, Gonge H. Resistance to group clinical supervision: A semistructured interview study of non-participating mental health nursing staff members. Int $\mathrm{J}$ Ment Health Nurs. 2018;27(2):783-93.

29. Estes BC, Estes BC, Shores M, Estes BC. Abusive Supervision and Nursing Performance. 2013;48(1).

30. Ali H, Abdallah N, Ahmed S. An educational program about quality of clinical supervision for first line nurse managers. 2018;(December).

31. O'Shea J, Kavanagh R, Roberts L, Connaire 'Shea. Clinical supervision for nurses working in mental health services: A Guide for Nurse Managers, Supervisors and Supervisees. 2020.

32. Mohamed R F, Mohamed Ahmed H. Clinical supervision factors as perceived by the nursing staff. J Nurs Educ Pract. 2019;9(6):67.

33. Noor S, Agianto, Nursalam, Setiawan H. Clinical supervision training to increase nurses' work performance in hospitals. Indian J Public Heal Res Dev. 2019;10(8):2751-5.
34. Martin P, Copley J, Tyack Z. Twelve tips for effective clinical supervision based on a narrative literature review and expert opinion. Med Teach. 2014;36(3):201-7.

35. Anggeria E, Maria. Hubungan supervisi dengan pelaksanaan asuhan keperawatan di ruang rawat inap lantai 10 Rumah Sakit Umum Royal Prima Medan. 2018;3(2):78-97.

36. Fowler J. Clinical supervision: From staff nurse to nurse consultat. 2012;21(22):2012.

37. Byrne L, Roennfeldt H, Wang $\mathrm{Y}$, O'Shea P. 'You don't know what you don't know': The essential role of management exposure, understanding and commitment in peer workforce development. Int J Ment Health Nurs. 2019;28(2):572-81.

38. Suryani J. Hubungan supervisi klinis manajerial dengan kepuasan kerja perawat. 2017;7:68-74.

39. Whitman M, Halbesleben J, Jolmes O. Abusive supervision and feedback aviodance: The mediating role of emotional exhaustion. J Organ Behav J Organiz Behav. 2012; 